an inflating universe to the conventionally expanding model, although there seems no reason to expect their scales to be limited in any way. More exotic types of phase transition have also been postulated, involving strings or walls of vacuum energy that, before eventually decaying, can generate inhomogeneities.

An alternative and even more radical approach is to dispense with the hot big bang entirely. It is the high temperature and entropy of this model that creates such difficulties for fluctuation growth. In an initially cold (or even lukewarm) big bang, spontaneous growth on stellar mass-scales appears likely, if not inevitable, during the early transition from a solid to a gaseous phase. This model may provide the required seeds, but of course it creates other difficulties, notably the need for alternative explanations of the cosmic background radiation and of the lightelement abundances, two pillars of the conventional big-bang theory.

Joseph Silk is on sabbatical leave from the University of California, Berkeley at the Institut d'Astrophysique, 98 bis Boulevard Aragon, 75014 Paris.

\title{
Island biogeography
}

\section{Variations in population density and extinction}

\section{from Mark Williamson}

UNTIL, recently, the biological study of plant and animal populations on islands has been focused principally on the number of species found, and population density has been largely ignored. That emphasis is now changing, and some new analyses of the population dynamics of species of spiders, lizards and birds on two groups of islands have helped to illuminate the control of population density, the probability of extinction and the detection of subtle habitat changes through changes in population density.

Standard approaches to island biology include plotting the number of species against the area of islands, as around New Zealand ', plotting numbers of extinctions and immigrants against the number of breeding species on an island ${ }^{2}$, and incidence curves ${ }^{3}$ showing the proportion of islands of a given size occupied by different species. All these are second-order results, the first-order ones being the effects of habitat density, geographical isolation and competition and predation on the population densities of the species of an island. The effect of dynamic interactions on the secondary phenomena has been particularly unclear ${ }^{2}$.

Schoener and Toft $^{4}$ show what might be done to clarify the importance of competition and predation by studying orb-web spiders on very small islands in the Bahamas. In some species of orb-web spiders, individuals can be counted on their webs. Spiders come in the middle of food chains, being predators of arthropods and prey for many vertebrates, though on the islands studied, which vary from $50 \mathrm{~m}^{2}$ to less than 1 hectare, the only vertebrates are lizards (mostly Anolis sagrei) and then only on some of the islands.

It seems that the spiders disperse to, and maintain populations on, such small islands with difficulty. Half the islands had no spiders, and there is a marked effect of distance from larger islands: no island more than $1.5 \mathrm{~km}$ from a large source island had any spiders. Allowing for this effect, islands with lizards had only onetenth the population density of all species of spiders of islands without lizards.

Is this the result of predation by the lizards, or competition with the lizards for other arthropods? The answer may be different for different species.

Populations of Gasteracantha cancriformis, a brightly coloured and thorny spider, do not seem to be affected by lizards; while Argiope argentata, a species readily taken by lizards, particularly lacks juveniles in its populations on lizard islands (juveniles build their webs closer to the ground and are more susceptible to predation). These two species suggest that predation is the cause but for Eustala cazieri, another edible species, there is again no effect of presence of lizard density, possibly because this species feeds by night as well as by day, which should reduce competition with lizards. Unravelling the effects of competition and predation is difficult because of the extreme variability in the population density of the spiders, which may also make their populations particularly prone to extinction.

Extinction has greatly affected the species list of birds on Barro Colorado Island, formed by the building of the Panama Canal at the beginning of the century. Between 15 and 60 species may have gone extinct compared with 161 breeding species known today ${ }^{5}$. By extensive use of mist net studies to determine population densities both on the island and on the mainland, $\operatorname{Karr}^{6}$ shows very neatly that, in general, the species that might be expected on the island, but that are not there, are those with particularly variable population densities on the mainland. Population variability seems both for these birds and for the Bahamian spiders to be more important than average population size as a predictor of extinction.
Whether extinction or an inability to immigrate determines the lower limit of size for an inhabited island for any species, as shown by incidence curves, again requires knowledge of population dynamics. Schoener and Schoener ${ }^{7}$ have experimented with populations of lizards (again mostly $A$. sagrei) on Bahamian islands. Islands of size down to $167 \mathrm{~m}^{2}$ have lizards, with population densities typically between $1-10 \mathrm{~m}^{2}$ and $1-100 \mathrm{~m}^{2}$. After the introduction of five to ten lizards, on islands varying in size from less than $1 \mathrm{~m}^{2}$ to 1 hectare, populations persisted for five years on all islands of $13 \mathrm{~m}^{2}$ or more but were extinguished within days on islands of $4 \mathrm{~m}^{2}$ or less.

The transition from extinction to persistent populations plotted against island area is remarkably sharp, and occurs at an area of about an order of magnitude less than found for natural populations. Perhaps hurricanes are responsible: populations of small islands may become extinct in storms, or lizards may only immigrate in the wake of storms.

Another way of looking at population persistence has been devised by Haila and Järvinen ${ }^{8}$. Instead of drawing incidence curves showing the presence or absence of particular species on islands of different sizes they have derived prevalence functions showing the population densities. On islands in the Alland archipelago in the Baltic, this technique brings out subtle differences in habitat requirements of two warblers, the Whitethroat (Sylvia communis) and the Blackcap (S. atricapilla), the former having increased densities on small islands where the latter is almost absent. The cause seems to be the scrubbier nature of the forests on the islands, with the trees only 10-12 m high compared with $16-18 \mathrm{~m}$ on the mainland.

Prevalence functions also bring out the relative suitability of different habitats for fieldfares (Turdus pilaris). When the population crashes, the island habitats are the more affected.

As new theories are developed to replace the popular but obsolete MacArthur and Wilson theory ${ }^{9}$, population dynamics will be a key feature, making island biogeography even more relevant to conservation than it has been ${ }^{10}$.

Mark Williamson is Professor in the Department of Biology at the University of York, York YOI SDD.

\footnotetext{
I. Williams, G.R. J. Biogeogr. 8. 439 (1981); N.Z. JlEcol. 5 . 86 (1982).

2. Williamson, M. Oikos (in the press): Island Populations (Oxford University Press, 1983).

3. Gilpin, M.E. \& Diamond, J.M. Nature 285, 568 (1980).

4. Schoener, T.W. \& Toft, C.A. Science 219, 1353 (1983).

Karr J.R. Am. Nat $119,220(1982)$

. Karr J.R. Ecology 63, 1975 (1982).

Schoener, T.W. \& Schoener, A. Nafure 302, 332 (1983).

8. Haila, Y. \& Jarvinen, O. Stud. A vian Biol. 6, 559 (1981)

. Haila, Y. \& Jarvinen, O in Conceptual Issues in Ecology (cd. Saarinen, E.) (Reidet, Dordrecht, 1982).
}

10. Higgs, A.J. J. Biogeogr. 8, 117 (1981). 